\title{
A PAISAGEM DAS BORDAS RODOVIÁRIAS: FORMAS CONFIGURADAS ENTRE A PREVISIBILIDADE E IMPREVISIBILIDADE DO PLANEJAMENTO URBANO
}

\author{
Gustavo Izabel ${ }^{1}$ \\ Rafaelle Barbosa ${ }^{2}$ \\ Paloma Ferreira ${ }^{3}$ \\ Ingrid Souza ${ }^{4}$ \\ Glauci Coelho ${ }^{5}$
}

\begin{abstract}
Resumo: Objetivando analisar a paisagem urbana das bordas rodoviárias, modelada entre a previsibilidade e imprevisibilidade do planejamento urbano. Tomamos como caso exemplar, o entroncamento da Rodovia Washington Luiz com o Arco Metropolitano, no bairro Figueira, em Duque de Caxias, RJ. O impacto causado na paisagem natural e urbana sem o planejamento da paisagem, tende a impactar áreas no processo de ocupação descontrolada. A consequência na paisagem é a modelagem de formas e usos para os espaços que não dialogam com as demais infraestruturas e nem com a tipo-morfologia urbana que caracteriza o lugar. O tema debatido pretende dar visibilidade a importância da pesquisa sobre as dinâmicas locais que tendem a ser impactadas por grandes intervenções de mobilidade urbana, como forma de antever e pensar o projeto urbano que media espaços públicos e privados num desenho urbano comprometido com a qualidade do lugar.
\end{abstract}

Palavras-chave: Paisagem urbana; Bordas; Planejamento urbano.

\footnotetext{
${ }^{1}$ Arquitetura e Urbanismo/UNIGRANRIO, Brasil. E-mail: gustavo.izabel@unigranrio.com.br.

2 Arquitetura e Urbanismo/UNIGRANRIO, Brasil. E-mail: rafaelle.barbosa@unigranrio.br.

3 Arquitetura e Urbanismo/UNIGRANRIO, Brasil. E-mail: palomaferreira@unigranrio.br

${ }^{4}$ Arquitetura e Urbanismo/UNIGRANRIO, Brasil. E-mail: ingridsds.aqr@unigranrio.br.

${ }^{5}$ Arquitetura e Urbanismo/UNIGRANRIO, Brasil. E-mail: coelhoglauci@unigranrio.edu.br.
} 